\title{
VALOR PERCEBIDO NO CURSO, PERCEPÇÃO DO PRESTÍGIO E IDENTIFICAÇÃO COM A PROFISSÃO: UMA ANÁLISE JUNTO A ESTUDANTES DE ADMINISTRAÇÃO E CONTABILIDADE
}

\author{
Course perceived value, perceived prestige \\ and professional identification: an analysis with \\ management and accounting students
}

Envio 16.07.08 / Aceite 10.08.08

\author{
Francisco José da Costa ${ }^{1}$ \\ Leonel Gois Lima Oliveira ${ }^{2}$
}

\begin{abstract}
Resumo
O propósito desta pesquisa foi o de analisar como os estudantes de Administração e de Contabilidade avaliam o curso e a profissão, considerando as perspectivas do valor no serviço recebido, do prestígio percebido na profissão e da identificação com a profissão. Foi realizada uma revisão de literatura sobre valor, prestígio e identificação, além de um estudo de campo junto a 337estudantes dos dois cursos, na cidade de Fortaleza. Os dados foram avaliados por meio de análises descritivas, análise de variância e análise de regressão múltipla. Quanto aos resultados, é possível destacar que: (1) as avaliações variam por curso, com os estudantes de Contabilidade percebendo mais valor do que os de Administração; (2) os principais fatores de influência sobre a percepção geral de valor foram: relação entre preço e qualidade, reputação da instituição, valor epistêmico e valor emocional. Os resultados indicam elementos para que gestores de cursos e de instituições educacionais possam planejar mais adequadamente a formação e desenvolver ações para manter a motivação dos alunos com o seu curso e com a sua profissão.
\end{abstract}

Palavras-chave: Valor percebido; Reputação; Identificação.

\footnotetext{
${ }^{1}$ Doutor em Administração, professor do Curso de Mestrado Acadêmico em Administração da Universidade Estadual do Ceará, Pesquisador na área de Marketing e Formação em Negócios. E-mail: franze@franzecosta.com.

${ }^{2}$ Mestrando em Administração pela Universidade Estadual do Ceará. Bolsista da CAPES. Email: leonelgois@gmail. com.
} 


\begin{abstract}
The purpose of this study was to examine how administration and accounting students evaluate their courses and profession, considering the aspects of value in the services received, the perceived prestige in the profession and identification with the profession. It was done a literature review on value, prestige and identification, and a field study with 337estudantes of two courses in the city of Fortaleza. The data were evaluated through descriptive analysis, analysis of variance and multiple regression analysis. From the results, it is possible to emphasize that: (1) the assessments vary by course, with accounting students perceiving more value than Administration ones; (2) the main factors of influence on the general perception of value were: relationship between price and quality, reputation of the institution, epistemic value and emotional value. The results indicate elements for managers of courses and of educational institutions to better plan the educational process and develop actions to maintain the motivation of students with their course and with his profession.
\end{abstract}

Keywords: Perceived value; Reputation; Identification.

\title{
1 Introdução
}

Os estudos acerca do ensino e da pesquisa em negócios cumprem importante papel no desenvolvimento do conhecimento da área, tanto por permitir um maior entendimento do processo de formação, como por indicar meios para adequá-lo às demandas, continuamente em transformação, impostas pela sociedade (aqui se entende que os cursos de Administração, Turismo e Contabilidade, reunidos em um só bloco no sistema de avaliação da Coordenação de Aperfeiçoamento de Pessoal de Nível Superior (CAPES), podem ser entendidos como uma única área, que se optou por chamar de negócios, nomenclatura assim verificada na literatura (MARION e MARION, 2006).

As análises geradas em periódicos direcionados ao assunto (especialmente em nível internacional) e em publicações em eventos (no Brasil, como área de eventos acadêmicos diversos e com um evento próprio para debater o assunto, o Encontro de Ensino e Pesquisa em Administração e Contabilidade [ENEPQ], da Associação Nacional de Pós-Graduação e Pesquisa em Administração [ANPAD]) são evidências de uma preocupação acadêmica com o assunto e têm servido para direcionar um aprimoramento contínuo do processo de formação de futuros profissionais de Administração e Contabilidade.

Acredita-se que esses tópicos sejam do interesse dos diversos profissionais envolvidos no processo de formação, incluindo professores, coordenadores de cursos, diretores de instituições de ensino e os próprios estudantes. Pelos múltiplos interessados e pelas diversas questões teóricas que podem ser levantadas, os estudos sobre a formação constituem um contexto amplo, com diversas possibilidades de estudos e temas de pesquisa.

Considerando esta realidade, este trabalho foi desenvolvido no intuito de analisar a formação em Administração e Contabilidade a partir da percepção dos alunos, buscando verificar especificamente o valor percebido no curso, a identificação pessoal do aluno com a profissão e a percepção de prestígio na profissão. Diversas questões são colocadas neste propósito: Como os estudantes percebem valor nos cursos? Como avaliam a futura profissão e como se avaliam em relação a esta profissão? Há variações de percepção? Se há, quais são estas variações e por que elas ocorrem? 
A partir dessas delimitações e questionamentos, foi definido como problema central desta pesquisa o seguinte: Como os estudantes de negócios avaliam seus cursos, considerando as perspectivas do serviço de formação recebido, da profissão e da identificação pessoal? Os objetivos foram: (1) analisar a percepção de valor dos estudantes no serviço de formação recebido, o nível de identificação destes com a profissão e sua percepção de prestígio na profissão; (2) avaliar as dimensões mais relevantes na percepção de valor dos estudantes.

Acredita-se na relevância do estudo na medida em que este pode possibilitar que gestores de instituições e coordenadores de cursos acessem informações e análises que possibilitem avaliar o posicionamento dos estudantes em formação, viabilizando, assim, o aprimoramento do planejamento das atividades nos cursos. Adicionalmente, acredita-se que os resultados possam servir de apoio para que os professores e autores de material didático possam melhor direcionar suas propostas pedagógicas.

O trabalho alinha-se, assim, a um contexto já bem encaminhado nos estudos desenvolvidos na área de ensino e pesquisa, como pode ser observado em avaliações exploratórias de anais de eventos e periódicos nacionais e internacionais. Trata-se aqui de apresentar as avaliações dos estudantes para os tópicos definidos, como forma de indicar o que os receptores e co-produtores do serviço (CLAYSON e HALEY, 2005; OBERMILLER, FLEENOR e RAVEN, 2005) pensam sobre: a formação, a profissão e si próprios, especificamente em relação a seus cursos.

O texto que segue é composto de quatro partes: inicialmente é feita a revisão de literatura, para fundamentar o trabalho; na seqüência, são apontados os procedimentos metodológicos utilizados na pesquisa de campo; em seguida, são apresentados os resultados e as discussões do trabalho empírico e, por fim, são apresentadas as considerações finais.

\section{Revisão teórica}

Na revisão de literatura, considerou-se pertinente analisar inicialmente o tema valor percebido e, em seguida, abordar os temas de prestígio profissional e de identificação dos estudantes com sua futura profissão. Deu-se ênfase aos tópicos que deram suporte ao trabalho de campo.

Com relação à percepção de valor, a literatura está extensamente desenvolvida no domínio da área de Marketing. A avaliação exploratória do tema indicou diversos caminhos e desafios específicos, tendo-se optado, aqui, por expor a conceituação de valor e comentários associados às dimensões do construto. Quanto à conceituação, pôde-se perceber um destaque especial para a proposta de Zeithaml (1988, p. 14), que define o valor como sendo a avaliação global da utilidade de um produto baseado na percepção do que é recebido e do que é dado.

Normalmente, essa definição é uma das mais aceitas nos estudos sobre o assunto, além de ter a vantagem de deixar clara a composição do valor na percepção dos clientes. Como é possível verificar, o valor passa, necessariamente, pela avaliação de duas dimensões: os benefícios e os sacrifícios. No contexto de maior desenvolvimento do tema (Marketing), esses tópicos já estão bastante aprofundados e cada um tem sua estrutura teórica e seus estudiosos específicos (COSTA, 2007).

Para os objetivos deste trabalho, merece destaque também a relevante contribuição de Sheth, Newman e Gross (1991), que avaliaram o valor em uma perspectiva multidimensional, definindo cinco categorias de valor, descritas a seguir: 
- o 'valor funcional', que se refere aos atributos do produto (bem ou serviço) que está sendo adquirido, estando mais associado às especificações técnicas do produto e a sua utilidade primária. Essa categoria tem sido normalmente associada ao construto qualidade e, de acordo com Sweeney e Soutar (2001), a sua relação com o preço;

- além dessa dimensão de valor, também é extremamente relevante a percepção de como o consumo se associa aos relacionamentos que se estabelecem entre as pessoas envolvidas no processo de consumo. Conforme argumentam Sheth, Newman e Gross (1991), há uma motivação social para o consumo, que se expressa pelo chamado 'valor social';

- um produto consumido também pode afetar os sentimentos dos compradores e consumidores, tanto de forma positiva como negativa. Tal fato ocorre em razão do 'valor emocional' associado ao consumo;

- há ainda diversos tipos de produtos comprados ou adquiridos que são fortemente motivados pela possibilidade que têm de gerar conhecimentos ou satisfazer a alguma curiosidade. Tal fato deve-se ao 'valor epistêmico' associado ao produto ou serviço;

- por fim, há circunstâncias em que uma determinada escolha de consumo está condicionada por algo em especial, sem as quais tal decisão seria relativizada. Segundo Sheth, Newman e Gross (1991), isso configura o 'valor condicional' que o consumo adquire como resultado de uma situação específica.

A proposta de Sheth, Newman e Gross (1991) serviu de base para diversas outras pesquisas, dada a clareza com que ficaram definidas as diversas dimensões de valor. Dentre os estudos que se basearam nessas categorias de valor, são destacados, para os objetivos deste artigo, os de Leblanc e Nguyen (1999) e o de Costa (2007), que desenvolveram análises tendo o valor como multidimensional, em um contexto empírico semelhante ao aqui definido (o primeiro em cursos de graduação e o segundo em cursos de pós-graduação lato sensu).

De acordo com o que foi previamente estabelecido, o direcionador para as análises deste trabalho foi a perspectiva dos estudantes. Uma vez que a análise de valor percebido aqui desenvolvida foi mais associada com o serviço da instituição de ensino, considerou-se que seria mais relevante, para uma análise consistente, que se avaliassem também outros aspectos complementares.

O entendimento foi de que a realidade de mercado exige dos profissionais de todas as áreas um melhor desempenho e, cada vez mais, eficiência. Sendo assim, o valor e a organização do conhecimento dependem da motivação e dos objetivos de cada indivíduo em um determinado momento (SILVA e CUNHA, 2002). Dentro desse contexto, o processo de avaliação profissional envolve diversos aspectos relevantes, dentre os quais: aspirações sociais, econômicas, afetivas e pessoais.

Sobre isso, Witter et al. (1992) dizem que a formação de um bom profissional decorre de muitas variáveis e que sofre, ao longo do processo, a influência de muitas outras. Os autores acreditam ainda que esse processo não ocorre somente no singular, mas também no social, ou seja, dizem que, dentre as motivações que levam os estudantes à sua escolha, está a construção social na qual ele se inclui.

Assim, decidiu-se por avaliar as percepções dos estudantes sobre o prestígio da profissão e sobre si mesmos em relação a essa profissão. Esses dois aspectos envolvem (conforme será comentado posteriormente) elementos de uma atitude e de uma percepção pessoal frente à profissão na qual os estudantes estão se formando. Nesses termos, tem-se, na sua análise, em conjunto com os elementos de valor, uma visão ampliada da avaliação que os estudantes fazem do serviço que recebem e da perspectiva futura em termos de satisfação pessoal e status social. 
Os dois temas (prestígio/reputação e identificação profissional) são tangenciados em estudos de várias áreas do conhecimento e têm um desenvolvimento teórico mais extenso no âmbito da sociologia das profissões, um campo que, segundo argumenta Freidson (1996), não despertou, historicamente, um grande interesse dos pesquisadores das Ciências Sociais. As avaliações exploratórias desenvolvidas para este trabalho indicaram que, até o presente momento, o tema ainda pode ser tido como pouco explorado. Verificou-se ainda uma grande assimetria nos estudos, com grande concentração dos estudos nas áreas de Saúde (especialmente Enfermagem), Direito e Educação.

Especificamente na análise do prestígio (ou de reputação) profissional, verificou-se uma forte concentração dos estudos na área de Enfermagem. Uma referência mais específica na área de Administração está presente em Bertero (2006), que categorizou os profissionais de administração em três grupos: burocratas, empreendedores e executivos. No entendimento do autor, há um elevado prestígio social nas figuras do executivo ou empreendedor (como fica evidenciado nas peças publicitárias das instituições de ensino), mas este aponta que a figura do burocrata é socialmente malvista (possivelmente em função das dificuldades conceituais em torno da idéia de burocracia). Nesta mesma profissão (Administração) foi observada uma concentração ainda em Costa, Brasileiro e Soares (2007), que analisaram os mesmos aspectos aqui verificados exclusivamente nesse curso. Já para Contabilidade, o tema foi somente tangenciado por alguns autores (MARION, 2001; LACERDA, REIS e SANTOS, 2007), conforme foi verificado na pesquisa bibliográfica empreendida.

Entende-se, por outro lado, que a reputação profissional seja da maior relevância para os profissionais desses três cursos, uma vez que consistem em profissões que, apesar de uma grande importância social, ainda carecem de uma identidade própria que as vinculem ao conhecimento técnico e acadêmico. Este estudo buscou abordar o tema, mesmo levando em conta as limitações para a construção de um referencial teórico sólido.

Uma definição bem delimitada de prestígio profissional não foi encontrada na literatura, nem mesmo nas áreas em que o tema é mais abordado. Tomando uma referência da área de Enfermagem, encontra-se em Lino (2004) uma abordagem do prestígio profissional como parte do conceito mais geral de satisfação profissional. Segundo essa autora, o prestígio (denominado pela autora como status) profissional refere-se à "importância ou significação percebida acerca do trabalho, tanto pelo ponto de vista individual como pelo ponto de vista de outros membros de um grupo social" (LINO, 2004, p. 14). Esta definição, apesar de seu conteúdo genérico, foi adotada para este trabalho.

A definição proposta indica a relevância do referencial externo na avaliação das profissões. Entende-se que, para negócios, tal referencial está fortemente vinculado às avaliações dos gestores e empresários acerca dos profissionais e, adicionalmente, à possibilidade de proeminência social gerada a partir do exercício da atividade em si.

Segundo defendeu Popkewitz (1991), freqüentemente as profissões desenvolvem seus serviços de forma a obter prestígio, poder e valor econômico, ou seja, desenvolvendo uma autoridade cultural e social. Também investigadores, como Marc Maurice e William Goode (apud NÓVOA, 1987), concluíram que era inútil estudar um grupo profissional por meio da observação de um tipo ideal de profissão sem colocar em causa os seus fundamentos, atributos sociais e o prestígio ao qual the cabia. Este artigo adota este entendimento como sendo pertinente para os cursos em análise, o que faz entender a necessidade de uma maior dedicação de pesquisadores para o entendimento do que é e de como se caracteriza o prestígio profissional para a grande área de negócios.

O terceiro aspecto definido para este estudo concerne à identificação pessoal dos estudantes com a sua futura profissão. A proposição é, portanto, que se avalie não somente 
o referencial da reputação da profissão, mas também como o futuro profissional se avalia em relação a esta mesma profissão.

Conforme apontou Campos (2000), a identidade profissional refere-se a um conjunto de características que torna uma pessoa semelhante àqueles que exercem uma atividade socialmente reconhecida. Nesse sentido, é evidente e expressiva a relação da identidade com o trabalho. Jacques (1997) reforça essa relação indicando que é a importância do trabalho na sociedade (consolidada pelo sistema capitalista, em que o trabalho tem papel fundamental na constituição do eu) que dá prestígio, relevância e exaltação ao papel de trabalhador, colocando-o em destaque entre os muitos papéis do indivíduo.

Nesses termos, o indivíduo reproduz sua estrutura social mediante processos de identificação, a qual não se constitui como mera imitação e que supõe um esforço inconsciente para reproduzir um ato, uma palavra ou um objeto. Segundo Nasio (1999), este objeto é uma identificação inconsciente, que é prévia à existência de outrem, uma representação que já se acha ali e na qual virá escorar-se a realidade externa da pessoa do outro ou de qualquer um de seus atributos já existentes ao longo da sua formação pessoal e/ou profissional.

Segundo Galindo (2004), além de definir identidade, é necessário circunscrever o campo no qual se trata a identidade profissional. Para a autora, enquanto o debate sobre identidade convida a considerar aspectos ligados ao nível individual, a idéia de profissional leva a pensar em aspectos do social.

A identificação está associada, portanto, com a satisfação (LINO, 2004) e com a perspectiva de compromisso profissional (BASTOS, CORREA e LIRA, 1998). Considerando essas observações, pode-se entender a identificação profissional como a percepção de vinculação pessoal a uma dada profissão, associada à percepção atual ou à perspectiva de satisfação pessoal com o exercício das atividades da referida profissão. Para este estudo, a proposição é avaliar a perspectiva atual dos estudantes em relação à satisfação e ao comprometimento futuro com a profissão escolhida.

É relevante ainda realçar a proximidade dos tópicos teóricos 'prestígio' e 'identificação', como observou Santos (1990). Para este autor, em seu estudo sobre aposentadoria, há uma forte aproximação da identificação com a idéia de prestígio, pois, segundo defende, o aspecto principal do conceito de identidade é o reconhecimento que emana das relações sociais e não de uma dimensão mais estritamente pessoal. Sob esse aspecto, entende-se que a formação de identidade requer um processo de reflexão e observação simultâneas, um processo que ocorre em todos os níveis de funcionamento mental e pelo qual o indivíduo se julga à luz daquilo que percebe ser a forma como os outros o julgam, em comparação com eles próprios e com uma tipologia que é significativa para eles (ERIKSON, 1972).

Ainda segundo Santos (1990), o indivíduo define-se a partir de como se reconhece no desempenho de papéis sociais e de como é reconhecido pelos outros no meio social. Nesses termos, a proximidade temática justifica a abordagem conjunta em um mesmo estudo, considerando, por outro lado, que o prestígio esteja mais condicionado a um contexto externo que a identificação, que é mais pessoal.

\section{Metodologia}

O trabalho foi desenvolvido em três etapas: procedimentos exploratórios, definição do instrumento e coleta de dados e trabalho empírico. Os procedimentos exploratórios foram desenvolvidos em duas fases: a primeira constou da pesquisa bibliográfica desenvolvida, exposta 
no item anterior; enquanto a segunda fase consistiu nos procedimentos exploratórios gerais, que foram relacionados à avaliação de trabalhos semelhantes, à análise de escalas utilizadas e à consulta a especialistas para fechamento dos construtos da pesquisa.

Para a coleta de dados, foi selecionado, como instrumento, o questionário. Foi decidido que o instrumento seria dividido em três blocos: o primeiro bloco contendo as variáveis de identificação relacionadas à formação, experiência e perspectivas futuras do estudante; o segundo bloco envolvendo as questões dos construtos do estudo; e, por fim, o terceiro bloco trazia questões sobre dados demográficos e socioeconômicos.

Para a operacionalização dos construtos associados à percepção de valor, analisou-se especialmente o artigo de Leblanc e Nguyen (1999), que estudaram a percepção de valor de estudantes de negócios, considerando seis dimensões, associadas à proposta de Sheth, Newman e Gross (1991, p. 19): valor funcional (1. relação preço/qualidade e 2. busca de satisfação), valor epistêmico, reputação institucional, valor emocional e valor social.

A análise pormenorizada da pesquisa de Leblance Nguyen (1999) indicou a possibilidade de melhorias, o que foi procedido baseando-se especialmente em Costa (2007). Este autor desenvolveu um estudo sobre a relação entre a percepção de valor e os comportamentos de reclamação e de boca a boca de estudantes de cursos de pós-graduação lato sensu da área de negócios. Na avaliação do autor, o valor foi operacionalizado em cinco dimensões, sendo três de benefício (qualidade, beneficio social e reputação) e duas de sacrifício (monetário e nãomonetário). Com base na avaliação individual de cada trabalho e de cada dimensão, decidiu-se pela análise do valor, neste trabalho, nas seguintes dimensões:

- Valor funcional (preço/qualidade): foi entendido da mesma forma que Leblanc e Nguyen (1999) e operacionalizado com três variáveis;

- Valor funcional (desejo de satisfação): foi entendido como avaliado em Leblanc e Nguyen (1999) e Costa (2007) e operacionalizado com cinco variáveis;

- Valor social: foi entendido com o mesmo sentido avaliado em Leblanc e Nguyen (1999) e em Costa (2007) e operacionalizado com cinco variáveis;

- Valor emocional: foi entendido com o mesmo sentido avaliado em Leblanc e Nguyen (1999) e operacionalizado com três variáveis;

- Valor epistêmico: foi entendido como relacionado ao beneficio de conhecimento do curso, como avaliado em Leblanc e Nguyen (1999), e operacionalizado com quatro variáveis;

- Valor de reputação: esta dimensão foi analisada com o mesmo sentido avaliado em Leblanc e Nguyen (1999) e Costa (2007), com ênfase especificamente na reputação da instituição. A operacionalização foi feita com cinco itens.

Além desses construtos, foi utilizada, na análise, a variável de 'percepção geral de valor', extraída de Leblanc e Nguyen (1999), cujo enunciado foi "Entendo que todos os gastos que tenho na realização de meu curso são compensados por tudo o que recebo". É relevante observar que, com essas delimitações, procurou-se manter o foco no nível do serviço que o estudante recebe e na instituição fornecedora do serviço.

$\mathrm{Na}$ análise do prestígio percebido na profissão, a avaliação foi feita com base em cinco variáveis, com sentido semelhante àquele utilizado na dimensão de valor de reputação. A diferença foi que, na avaliação acima, a ênfase foi na instituição e, aqui, na profissão.

Para a identificação do estudante com a profissão, o propósito foi avaliar o quanto o estudante se vê identificado com a profissão na qual está se formando. A operacionalização foi feita com cinco itens gerados a partir de Farrell (2006), que avaliou a auto-identificação de estudantes de marketing com a profissão. 
Todas as variáveis foram apresentadas como afirmação, nas quais era solicitado que o respondente apresentasse seu grau de concordância em uma escala de Likert de 7 pontos, com extremos de 1 (indicando discordância total) e 7 (indicando concordância total). Para a aplicação do questionário, foram adotadas as configurações a seguir:

- Universo da Pesquisa: o universo foi constituído pelos estudantes de cursos de bacharelado em Administração e em Contabilidade das instituições de Ensino Superior de Fortaleza (Ceará);

- Amostra: a amostra total foi de 337 estudantes, distribuídos entre os dois cursos de referência (Administração e Contabilidade), abordados diretamente em seis instituições, selecionados conforme a acessibilidade e a conveniência;

- Método de Coleta: a coleta de dados foi procedida pelos autores. O procedimento básico consistia no pedido de apoio dos professores das diversas disciplinas do curso, considerando a distribuição dos alunos em todo o período do curso. Os questionários da amostra foram aplicados entre os meses de março do ano de 2007 a março do ano de 2008.

Os procedimentos estatísticos para os dados coletados foram de quatro tipos: análises exploratórias preliminares, análise descritiva, análise de variância e análise de regressão. A avaliação exploratória preliminar consistiu em analisar a massa de dados coletados, como forma de identificar e corrigir eventuais dificuldades, como a existência de valores perdidos (missing values), a existência de observações atípicas (outliers) e de (não) normalidade das variáveis (HAIR et al., 2005). As verificações não indicaram a necessidade de maiores intervenções nos dados, viabilizando, assim, os procedimentos subseqüentes.

Para a análise descritiva dos dados, a primeira concentração foi nas freqüências de variáveis sócio-demográficas da amostra. Também foram apresentadas e avaliadas as estatísticas descritivas (média e desvio-padrão) dos construtos. Com base nos dados de cada um dos construtos, verificaram-se, por meio da técnica de análise de variância (ANOVA), as diferenças dos resultados dos construtos para variável associada ao curso. Ainda de posse dos resultados dos construtos, decidiu-se proceder a uma maior exploração das relações a partir da técnica de análise de regressão múltipla, com o propósito de avaliar a consistência das relações entre o valor percebido geral e suas dimensões aqui estudadas, e verificar ainda a importância de cada uma das dimensões na formação da percepção geral.

Todos os procedimentos foram desenvolvidos com suporte nas recomendações de autores especialistas nas técnicas utilizadas (MALHOTRA, 1999; HAIR et al., 2005) e foram feitos com apoio do software SPSS, versão 13.

\section{Resultados}

A discussão dos resultados desta pesquisa está organizada em quatro momentos. Nos dois primeiros, são apresentados os resultados das análises descritivas da amostra. O terceiro momento apresenta a análise dos construtos por curso e a análise de regressão.

\subsection{Informações sobre a amostra}

A amostra foi composta por 50,4\% de estudantes de Administração e 49,6\% de Contabilidade. Na distribuição por ano, teve-se 27,9\% do primeiro, 27,0\% do segundo, 24,3\% do terceiro e $20,8 \%$ do quarto ano (para melhorar a consistência das análises comparativas, 
não foram incluídos no estudo os estudantes de quinto ano, o que se observou somente em duas instituições). Considera-se que a proporção praticamente igual por curso contribuiu para as análises comparativas subseqüentes. O mesmo ocorre em relação ao ano de curso, também com distribuição equilibrada e decrescente em relação aos anos, correspondendo, assim, à realidade observada de redução do número de alunos por curso na medida em que o tempo passa.

Quando à idade, 22,6\% dos respondentes apontaram ter até 20 anos, 26,1\% indicaram idade 'acima de 20 até 22 anos', 16,3\% indicaram idade 'acima de 22 e até 24 anos', 13,6\% apontaram idade 'acima de 24 e até 26 anos' e, ainda, 21,4\% indicaram ter 'acima de 26 anos'. A amostra foi composta de $51,3 \%$ de homens e $48,7 \%$ de mulheres. Com relação ao estado civil, obteve-se um percentual de $82,2 \%$ de solteiros, $13,9 \%$ de casados e $3,9 \%$ apontaram 'outros' como resposta.

Esses dados deixam claro que os respondentes foram preponderantemente jovens, estavam ainda nas primeiras fases de sua vida profissional e vão ao encontro do que é esperado em pesquisas com estudantes de graduação, sugerindo, assim, que, embora a amostragem tenha sido por conveniência, os dados se aproximam, nesses requisitos, às condições reais do universo.

Com relação à renda, observaram-se os seguintes percentuais: 19,6\% dos respondentes têm renda familiar 'até $\mathrm{R} \$ 1.000,00$ '; $26,2 \%$ têm renda familiar 'acima de $R \$ 1.000,00$ até $\mathrm{R} \$$ $2.000,00^{\prime} ; 18,8 \%$ têm renda familiar 'acima de $R \$ 2.000,00$ até $R \$ 3.000,00$ '; 14,0\% têm renda familiar 'acima de $R \$ 3.000,00$ até $R \$ 4.000,00$ '; e 21,4\% têm renda familiar 'acima de $\mathrm{R} \$ 4.000,00^{\prime}$.

\subsection{Informações relacionadas ao curso}

Os respondentes foram inicialmente questionados sobre sua experiência com atividades associadas ao curso. Um percentual elevado (57,3\%) informou ter experiência profissional na área do curso (na ocasião da pesquisa) e 42,7\% indicaram não ter essa experiência. A grande maioria $(71,9 \%)$ dos respondentes informou estar trabalhando em tempo integral $(49,1 \%)$ ou parcial $(22,8 \%)$ e $28,1 \%$ indicaram não estar trabalhando, seja por desemprego seja por afastamento do trabalho.

Os estudantes foram questionados sobre os motivos pelos quais haviam decidido por seus cursos. Os resultados indicaram que $47,5 \%$ dos estudantes buscaram inicialmente a preparação para um emprego (público ou privado) e somente $13,1 \%$ buscaram adquirir conhecimentos para abrir seu próprio negócio. Um total de 16,0\% informou a melhoria da prática profissional como principal razão, um total também de 16,0\% afirmou estar ali para se preparar para gerenciar empresas da própria família ou por exigência do emprego e, ainda, $8,0 \%$ informaram 'outros' como resposta.

Perguntados sobre o que pretendiam em relação ao trabalho após a conclusão do curso, aproximadamente dois terços dos respondentes (61,3\%) informaram o interesse inicial por um emprego em organização pública ou privada. Cerca de um quarto $(22,9 \%)$ informou pretender trabalhar em sua própria empresa ou na empresa da família e, ainda, 15,8\% indicaram a intenção de criar seus próprios negócios (9,3\% apontaram 'outros' como resposta).

Os resultados dos últimos dois parágrafos apontam uma forte orientação dos estudantes para o emprego, tanto pela motivação inicial para o curso como na condição atual, ao lado de um baixo interesse empreendedor. Fica claro que a proporção de estudantes com pretensão de seguir para um emprego $(61,3 \%)$ é bem maior que a proporção de estudantes que teve 
o emprego como principal motivação para o curso (47,5\%). Dentre as justificativas para esta diferença, pode-se dizer que se buscou avaliar o potencial condicionamento do ano dos estudantes no curso, não se tendo encontrado relação estatisticamente significativa.

Os estudantes também foram questionados sobre o que pretendiam em relação aos estudos e pouco mais da metade dos estudantes $(50,4 \%)$ informou pretender cursar uma especialização, enquanto $20,8 \%$ apontaram interesse inicial por um curso de mestrado. Ao total, observou-se que, aproximadamente, sete de cada dez estudantes $(71,2 \%)$ têm interesse em seguir com estudos de pós-graduação, indicando a percepção de que a graduação não é suficiente para uma formação profissional consistente. Para os demais respondentes, obteve-se o seguinte: 9,2\% indicaram não ter interesse em estudos após a formatura, 13,9\% pretendem fazer outro curso de graduação, enquanto 5,6\% indicaram 'outros' como resposta.

\subsection{Análise dos construtos da pesquisa}

O primeiro objetivo deste estudo foi avaliar a percepção de valor na formação, a identificação profissional e a percepção de prestígio na profissão. Para atender a este objetivo, verificaram-se as estatísticas descritivas dos construtos e foram analisadas ainda as relações entre o valor percebido geral e as dimensões de valor analisadas, além da variação dos construtos em algumas das variáveis categóricas da pesquisa (para as análises das medidas, dado que a escala utilizada foi de 7 pontos, adotou-se, como critério de análise, as seguintes médias: valores até 4 são baixos, de 4 a 5,5 são intermediários e acima de 5,5 são elevados; para os desvios-padrão, os critérios foram: valores até 1,2 são baixos, de 1,2 a 1,8 são intermediários e acima de 1,8 são elevados).

Com exceção do valor percebido geral, os construtos da pesquisa foram avaliados com a verificação das estatísticas descritivas e com a extração da confiabilidade das variáveis associadas a cada construto, procedimento realizado por meio da análise do coeficiente Alpha de Cronbach. Após os devidos ajustes, as variáveis finais foram compostas pelas médias das entradas correspondentes aos construtos para formar as medidas de cada um desses construtos, em conformidade com as recomendações de Bagozzi e Edwards (1998). Os resultados agregados por construto, considerando uma medida geral e por curso, juntamente com a confiabilidade final, encontram-se na Tabela 1. 
Tabela 1 - Medidas dos construtos em geral e por curso

\begin{tabular}{l|c|c|c|c|c|c|c}
\hline \multirow{2}{*}{ Variáveis } & \multirow{2}{*}{ Alpha } & \multicolumn{2}{c|}{ Geral } & \multicolumn{2}{c}{ Administração } & \multicolumn{2}{c}{ Contabilidade } \\
\cline { 4 - 8 } & & Média & Desvio & Média & Desvio & Média & Desvio \\
\hline $\begin{array}{l}\text { Valor geral } \\
(\mathrm{F}=11,670, \mathrm{p}<0,005)\end{array}$ & - & 4,90 & 1,49 & 4,63 & 1,52 & 5,17 & 1,42 \\
\hline $\begin{array}{l}\text { Valor funcional }{ }^{*} \\
(\mathrm{~F}=14,225, \mathrm{p}<0001)\end{array}$ & 0,866 & 4,62 & 1,45 & 4,33 & 1,56 & 4,91 & 1,28 \\
\hline $\begin{array}{l}\text { Valor funcional } 2^{* *} \\
(\mathrm{~F}=8,604, \mathrm{p}<0,005)\end{array}$ & 0,605 & 4,66 & 1,36 & 4,45 & 1,33 & 4,88 & 1,36 \\
\hline $\begin{array}{l}\text { Valor social } \\
(\mathrm{F}=1,002, \mathrm{p}=0,318)\end{array}$ & 0,655 & 5,29 & 0,90 & 5,34 & 0,85 & 5,24 & 0,95 \\
\hline $\begin{array}{l}\text { Valor emocional } \\
(\mathrm{F}=5,319, \mathrm{p}<0,05)\end{array}$ & 0,649 & 5,51 & 0,91 & 5,39 & 0,92 & 5,62 & 0,89 \\
\hline $\begin{array}{l}\text { Valor epistêmico } \\
(\mathrm{F}=0,193, \mathrm{p}=0,661)\end{array}$ & 0,742 & 5,68 & 0,92 & 5,70 & 0,83 & 5,66 & 1,00 \\
\hline $\begin{array}{l}\text { Valor de reputação } \\
(\mathrm{F}=0,272, \mathrm{p}=0,603)\end{array}$ & 0,795 & 5,51 & 0,86 & 5,54 & 0,84 & 5,49 & 0,90 \\
\hline $\begin{array}{l}\text { Identificação } \\
(\mathrm{F}=0,000, \mathrm{p}=0,984)\end{array}$ & 0,893 & 5,56 & 1,16 & 5,56 & 1,09 & 5,56 & 1,23 \\
\hline $\begin{array}{l}\text { Prestígio na profissão } \\
(\mathrm{F}=0,486, \mathrm{p}=0,486)\end{array}$ & 0,836 & 5,25 & 0,96 & 5,29 & 0,95 & 5,22 & 0,97 \\
\hline
\end{tabular}

Notas: *Relação preço/qualidade; **Busca de satisfação

Fonte: Dados da pesquisa

Analisando os resultados, pode-se verificar que todos os construtos apresentaram valores de Alpha satisfatórios, com exceção dos construtos 'valor funcional - busca de satisfação' (Alpha $=0,605)$, 'valor social' (Alpha $=0,655)$ e 'valor emocional' (Alpha $=0,649)$ com valores que, apesar de baixos, ainda estão acima de 0,60, que é considerado limite mínimo para se aceitar a confiabilidade (MALHOTRA, 1999). Os resultados são comentados a seguir:

- O valor percebido geral foi mensurado com apenas uma variável (cf. Metodologia). As médias apresentaram valores intermediários, porém é possível observar que a média no curso de Contabilidade $(5,17)$ foi maior que a média de Administração $(4,63)$. Também se observou que os desvios-padrão das duas áreas ficaram, de maneira geral, intermediários;

- Para o valor funcional percebido (compensação de preço por qualidade), mantiveramse as três variáveis, e os resultados indicaram nesta dimensão de valor, em geral, uma percepção nível intermediário (média 4,62), porém a média de Contabilidade $(4,91)$ foi mais elevada que a de Administração $(4,33)$. A dispersão geral foi intermediária, porém, em Contabilidade, os estudantes se mostraram mais convergentes no posicionamento apontado;

- Para o valor funcional percebido (busca de satisfação), alcançou-se uma confiabilidade aceitável com quatro das cinco variáveis inicialmente definidas. A média geral $(4,66)$ e as médias por curso (Administração - 4,45; Contabilidade - 4,88) indicaram uma avaliação intermediária, apesar de o curso de Contabilidade ter apresentado uma média mais elevada. O nível de dispersão foi, em geral, intermediário, embora tenha sido menor em Administração;

- Para o valor social percebido, uma boa confiabilidade foi alcançada com as cinco variáveis previamente definidas. Pela média geral $(5,29)$, foi possível observar uma boa avaliação dessa dimensão, tendo-se verificado que a média mais elevada foi dada pelos estudantes de Administração $(5,34)$, que teve também a menor dispersão, apesar de, em todos os outros casos (geral ou por curso), os valores de dispersão serem baixos; 
- Para o valor emocional percebido, alcançou-se uma boa confiabilidade com as quatro variáveis inicialmente propostas. A média geral $(5,51)$ indicou uma boa avaliação do valor emocional e aqui não houve diferenças significativas por curso. Os valores de dispersão foram baixos em todas as alternativas de verificação;

- Para o valor epistêmico percebido, alcançou-se uma boa confiabilidade com as quatro variáveis previamente definidas. A média geral $(5,68)$ indicou uma avaliação muito positiva dessa dimensão pelos alunos, e os resultados não apresentaram variação por curso. Também aqui os valores de dispersão foram baixos, indicando uma posição bastante convergente por parte dos estudantes;

- Para o valor de reputação percebida, alcançou-se uma boa confiabilidade com as cinco variáveis inicialmente propostas. A média geral pode ser entendida como elevada e não houve variações por curso. A indicação foi, portanto, de uma avaliação bastante positiva por parte dos estudantes, inclusive uma elevada convergência de posições;

- Para a identificação com a profissão, alcançou-se uma boa confiabilidade com a exclusão de uma das cinco variáveis inicialmente propostas. A média geral e as médias em Administração e Contabilidade foram elevadas (todas iguais a 5,56). Os valores de dispersão foram de nível intermediário, apesar de o curso de Administração ter apresentado uma dispersão mais baixa;

- Para o prestígio percebido na profissão, alcançou-se uma boa confiabilidade com as cinco variáveis iniciais. A média geral $(5,25)$ indicou uma percepção de prestígio na profissão intermediária, assim como o valor por cursos, mesmo tendo sido indicada diferença entre as médias, com uma média mais elevada para Administração $(5,29)$ e uma média mais baixa para Contabilidade $(5,22)$. Em todos os casos, a dispersão foi baixa.

Esses resultados, especificamente nas dimensões de valor, indicam uma menor percepção para o valor percebido geral e para as duas dimensões de valor funcional (preço/ qualidade e busca de satisfação) em relação aos demais, provavelmente por serem essas as dimensões de valor na qual estão explícitos os elementos de sacrifício (preço) e de perspectivas profissionais. Já a percepção de valor epistêmico, apresentou médias elevadas para quaisquer das medições realizadas, o que é compreensível, pois esse é o benefício primordial em uma instituição de ensino superior.

Para a dimensão de valor emocional, a média geral ficou em nível elevado. Para as dimensões de valor social, de reputação e funcional (busca de satisfação), as médias gerais ficaram em nível intermediário. Os motivos para essa maior criticidade dos estudantes de Administração e de Contabilidade não são, a priori, claros, porém pode-se supor que os estudantes investigados percebem a importância que seus respectivos cursos e atuações profissionais têm para a sociedade, uma vez que, em última instância, são responsáveis pelo desempenho dos negócios e pelo desenvolvimento econômico.

Já com relação à identificação pessoal com a profissão e a percepção de prestígio no curso, as médias foram também intermediárias. Tal resultado é compreensível pelo fato de os cursos de Administração e Contabilidade terem um direcionamento amplo em termos de tipos de organizações e setores possíveis de atuação.

Para atender ao segundo objetivo proposto para este estudo e como forma de confirmar as relações entre o valor percebido geral e as seis dimensões analisadas, considerando-se ainda a relevância de se conhecer quais das dimensões acima exercem maior influência sobre o valor percebido geral, decidiu-se proceder a uma análise de regressão múltipla. Utilizando- 
se o método backward, o valor percebido geral foi posto como variável dependente e as seis dimensões de valor foram postas como independentes. Os resultados estão expostos na Tabela 2 .

Tabela 2 - Resultados da regressão múltipla

\begin{tabular}{|c|c|c|c|c|c|}
\hline Modelo & Estat ística & Funcio. 1 & Emocio. & Reputa. & Epistê. \\
\hline \multirow{3}{*}{ Geral $\left(R^{2}=0,516\right)$} & Coeficiente $(\beta)$ & 0,490 & 0,113 & 0,168 & 0,123 \\
\hline & Estatística $\mathrm{t}$ & 10,724 & 2,151 & 3,559 & 2,379 \\
\hline & Signi. (p) & 0,000 & 0,032 & 0,000 & 0,018 \\
\hline \multirow{3}{*}{ Administração $\left(R^{2}=0,597\right)$} & Coeficiente $(\beta)$ & 0,569 & 0,166 & 0,206 & - \\
\hline & Estatística t & 9,536 & 2,613 & 3,483 & - \\
\hline & Signi. (p) & 0,000 & 0,010 & 0,001 & - \\
\hline \multirow{3}{*}{ Contabilidade $\left(R^{2}=0,421\right)$} & Coeficiente $(\beta)$ & 0,319 & - & 0,205 & 0,264 \\
\hline & Estatística $t$ & 4,359 & - & 2,823 & 3,493 \\
\hline & Signi. (p) & 0,000 & - & 0,005 & 0,001 \\
\hline
\end{tabular}

Fonte: Pesquisa Direta.

Pelos dados da Tabela 2, fica evidente que a dimensão de maior influência (em todas as verificações) é do valor funcional, entendido como a compensação entre a qualidade e o preço $(\beta=0,490 p<0,001$ - geral; $\beta=0,569, p<0,001$ - Administração; $\beta=0,319, p<0,001$ - Contabilidade). Tal resultado evidencia a forte atenção dada pelos estudantes aos aspectos relacionados à qualidade do serviço prestado e à compensação dessa qualidade pelo preço que pagam.

Já o valor de reputação confirmou sua relevância na composição do valor percebido geral em todas as verificações $(\beta=0,168, p<0,001$ - geral; $\beta=0,206, p<0,005$ - Administração; $\beta=0,205, p<0,005$ - Contabilidade), o que reafirma a importância da reputação das instituições na formação do valor percebido em cursos de graduação. No estudo de Costa (2007), que foi orientado com estudantes de pós-graduação, esta relação não se confirmou, o que sugere que há variações na avaliação da reputação institucional de acordo com o nível do curso.

Quanto às demais dimensões e valor, os resultados variaram por curso. Assim, o valor epistêmico mostrou-se um preditor significativo em geral $(\beta=0,123, p<0,05)$ e em Contabilidade $(\beta=0,264, p<0,05)$, porém, em Administração, a relação não foi significativa. Já o valor emocional apresentou influência significativa em geral $(\beta=0,113, p<0,05)$ e para o curso de Administração $(\beta=0,166, p<0,05)$.

Merece destaque o fato de que outras dimensões de valor, como o valor social e o valor funcional de busca de satisfação, a priori relevantes na escolha de uma instituição ou curso, não tenham apresentado influência no valor percebido geral em qualquer das manipulações. Especificamente em relação ao valor social, também no estudo de Costa (2007) essa relação não foi significativa, indicando a necessidade de maiores explorações sobre o sentido e a lógica dessa relação. Uma explicação possível é que tal observação seja condicionada pela percepção de que os benefícios sociais são conseqüências do serviço e não uma oferta da instituição.

\section{Considerações finais}

Este estudo partiu do entendimento de que há uma necessidade de motivar adequadamente os futuros profissionais da área de negócios e que esta motivação passa pela 
oferta de elevado valor por parte das instituições, por uma avaliação consistente da futura profissão e, ainda, por uma real identificação do futuro profissional com sua profissão. A pesquisa aqui desenvolvida abordou esses tópicos, avaliando diferenças, nuances e os tipos possíveis que configuram os estudantes de Administração e Contabilidade.

Os resultados descritos na análise de dados indicam que o trabalho atingiu adequadamente os seus objetivos, gerando, assim, informações relevantes para os gestores de cursos e de instituições de ensino superior, que podem viabilizar um melhor direcionamento no processo de formação.

Deve-se ressaltar, desde já, que os resultados foram limitados, uma vez que a amostra foi restrita a instituições cearenses, além do fato de a amostragem ter sido feita por conveniência. As observações e as conclusões devem, portanto, levar em conta esses fatores. Assim, apresentam-se, a seguir, as principais conclusões, desafios e recomendações de outras explorações e estudos baseados no trabalho desenvolvido.

$\mathrm{Na}$ análise da percepção de valor, merece destaque o fato de todas as avaliações terem sido de intermediárias a elevadas, com melhores avaliações dos estudantes provenientes do curso de Contabilidade. Adicionalmente, destacou-se que a formação do valor percebido geral varia por curso, tendo-se identificado que o valor funcional de compensação de preço e qualidade, além de valor de reputação, são fatores de influência tanto em geral quanto em nível de curso. Já as outras dimensões ou apresentaram influência parciais (valor epistêmico para o nível geral e Contabilidade e valor emocional em geral e para Administração), ou não apresentaram influência alguma (valor funcional de busca de satisfação e valor social). Caberiam, assim, outras verificações e pesquisas, em busca de novos avanços e uma melhor compreensão das dimensões de valor percebido pelos clientes de instituições de ensino.

Teoricamente este estudo foi realizado com o propósito de contribuir com a área de estudos de ensino e pesquisa em Administração e Contabilidade. A análise foi, portanto, restrita aos estudantes desses cursos, somente na cidade de Fortaleza. Acredita-se que os resultados das análises seriam mais consistentes se envolvessem estudantes de outras áreas geográficas e mesmo de outras áreas profissionais. Seria relevante, assim, uma replicação deste estudo em outros estados ou cidades brasileiras, de preferência com métodos de amostragem mais rigorosos. Recomenda-se, ainda, que este trabalho seja replicado em outros cursos, como Direito, Medicina, dentre outros, para que sejam realizadas comparações com os resultados aqui verificados.

Em nível prático, os resultados deixam claros alguns dos desafios para as instituições de ensino, para os professores, para os atores de materiais didáticos e, até mesmo, para os órgãos responsáveis pela profissão. Acredita-se, portanto, que os resultados representem informações relevantes para que agentes do processo de formação direcionem adequadamente suas atividades.

\section{Referências}

BAGOZZI, R. P.; EDWARDS, J. R. A general approach for representing constructs in organizational research. Organizational

Research Methods, v. 1, n. 1, p. 45-87, 1998.
BASTOS, A. V. B.; CORREA, N. C. N.; LIRA, S. B. Padrões de comprometimento com a profissão e a organização: o impacto de fatores pessoais e da natureza do trabalho. In: ENCONTRO ANUAL DA ASSOCIAÇÃO NACIONAL DE

Rev. Adm. UFSM, Santa Maria, v. 1, n. 3, p. 453-468, set./dez. 2008 
PÓS-GRADUAÇÃO EM ADMINISTRAÇÃO ENANPAD, 22., Foz do Iguaçu, 1998. Anais eletrônicos... Foz do Iguaçu: ANPAD, 1998. BERTERO, C. O. Ensino e pesquisa em Administração. São Paulo: Thomson Learning, 2006.

CAMPOS, R. Identidade profissional. In: FIDALGO, F.; MACHADO, L. Dicionário da educação profissional. Belo Horizonte: Núcleo de Estudos sobre Trabalho, 2000.

CLAYSON, D. E.; HALEY, D. A. Marketing models in education: students as customers, products, or partners. Marketing Education Review, v. 15, n. 1, p. 1-11, Spring 2005.

COSTA, F. J. A influência do valor percebido pelo cliente sobre os comportamentos de reclamação e boca a boca: uma investigação em cursos de pós-graduação lato sensu. 240f. Tese (Doutorado em Administração de Empresas) - Fundação Getúlio Vargas - Escola de Administração de Empresas de São Paulo, São Paulo, 2007.

COSTA, F. J.; BRASILEIRO, A. S. B.; SOARES, A. A. C. Formação em Administração na perspectiva do aluno: valor percebido no curso, percepção do prestígio e identificação com a profissão. In: ENCONTRO DE ENSINO E PESQUISA EM ADMINISTRAÇÃO E CONTABILIDADE ENEPQ, 1., Recife, 2007. Anais eletrônicos... Recife: ANPAD, 2007.

FARRELL, C. The development of a marketing self-efficacy scale: an assessment of reliability and construct validity. Marketing Education Review, v. 16, n. 3, p. 25-34, 2006.

FREIDSON, E. Para uma análise comparada das profissões: a institucionalização do discurso e do conhecimento formais. Revista Brasileira de Ciências Sociais, v. 11, n. 31, p. 141-154, jun. 1996.

GALINDO, W. C. M. A construção da identidade profissional docente. Psicologia: ciência e profissão, v. 24, n. 2, p. 14-23, jun. 2004.

HAIR, J. F. et al. Análise multivariada de dados. 5. ed. Porto Alegre: Bookman, 2005.
JACQUES, M. G. Identidade e trabalho. In: CATTANI, A. D. Trabalho e tecnologia: dicionário crítico. Porto Alegre: Vozes; Ed. Universitária, 1997.

LACERDA, J. R.; REIS, S. M.; SANTOS, N. A. Os fatos extrínsecos e intrínsecos que motivam os alunos na escolha e na permanência no curso de Ciências Contábeis: um estudo da percepção dos discentes numa universidade pública. In: ENCONTRO DA ASSOCIAÇÃO NACIONAL DE PÓS-GRADUAÇÃO E PESQUISA EM ADMINISTRAÇÃO, 31., Rio de Janeiro, 2007. Anais eletrônicos... Rio de Janeiro: ANPAD, 2007.

LEBLANC, G.; NGUYEN, N. Listening to the customer's voice: examining perceived service value among business college students. The International Journal of Educational Management, v. 13, n. 4, p. 187-198, 1999.

LINO, M. M. Satisfação profissional entre enfermeiras de UTI: adaptação transcultural do Index of Work Satisfaction (IWS). $238 f$. Tese (Doutorado em Enfermagem) - Escola de Enfermagem da Universidade de São Paulo, São Paulo, 2004.

MALHOTRA, N. K. Marketing research: an applied orientation. 3. ed. New Jersey: PrenticeHall, 1999.

MARION, J. C. O ensino da Contabilidade: o professor de ensino superior de contabilidade. 2. ed. São Paulo: Atlas, 2001.

MARION, J. C.; MARION, A. L. C. Metodologias de ensino na área de negócios. São Paulo:

Atlas, 2006.

NASIO, J. D. Sete conceitos em Psicanálise. Rio de Janeiro: Zahar, 1999.

NÓVOA, A. Les temps des professeurs: analyse socio-historique de la profession enseignante au Portugal (XVIII-XX Siècle). Lisboa: I.N.I.C., 1987.

OBERMILLER, C.; FLEENOR, P.; RAVEN, P. Students as customers or products: perceptions and preferences of faculty and students.

Marketing Education Review, v. 15, n. 2, p. 2736, Summer 2005. 
POPKEWITZ, T. A political sociology of educational reform: power/knowledge in teaching, teacher education, and research. New York: Teachers College Press, 1991.

SANTOS, M. F. S. Identidade e aposentadoria. São Paulo: EPU, 1990.

SHETH, J; NEWMAN, B. I.; GROSS, B. L. Consumption values and market choice: theory and applications. Ohio: South Western, 1991.

SILVA, E. L.; CUNHA, M. V. A formação profissional no século XXI: desafios e dilemas. Ciência da Informação, v. 31, n. 3, p. 77-82, set./ dez. 2002.
SWEENEY, J. C.; SOUTAR, G. N. Consumer perceived value: the development of a multiple item scale. Journal of Retailing, n. 77, p. 203220, 2001.

WITTER, C. et al. Formação e estágio acadêmico em Psicologia no Brasil. In: FRANCISCO, A. L.; KLOMFAHS, C. R.; ROCHA, N. M. D. (Orgs.). Psicólogo brasileiro: construção de novos espaços. Campinas: Átomo, 1992.

ZEITHAML, V. A. Consumer perceptions of price, quality, and value: a means-end model and synthesis of evidence. Journal of Marketing, $v$. 52, p. 2-22, Jul. 1988. 